\title{
ABORDAGENS SOBRE O PROCESSO DE DESERTIFICAÇÃO: UMA REVISÃO DAS EVIDÊNCIAS NO RIO GRANDE DO NORTE
}

Jane Azevedo de Araújo ${ }^{1}$

Raquel Franco de Souza ${ }^{2}$

\begin{abstract}
Resumo: A desertificação tornou-se tema relevante nos debates sobre a degradação das terras, feitos pela Organização Mundial das Nações Unidas, que é empenhada em, junto com os países afetados, combatê-la. As áreas criticamente atingidas pelo fenômeno no Brasil estão localizadas na região Nordeste. O estado do Rio Grande do Norte, por exemplo, apresenta uma área fortemente afetada, denominada de Núcleo de Desertificação do Seridó, compreendendo seis municípios. Este artigo tem como objetivo apresentar uma revisão de literatura sobre o processo de desertificação, com destaque para o panorama do fenômeno no estado do Rio Grande do Norte, na região do Seridó, especialmente no município de Parelhas. Sendo assim, o artigo poderá ser consultado como base para futuros estudos na área e em outros locais que apresentem características semelhantes.
\end{abstract}

Palavras-chave: Degradação Ambiental; Semiárido; Parelhas; Cerâmica

\section{APPROACHES ON THE PROCESS OF DESERTIFICATION: A REVIEW OF THE EVIDENCES IN RIO GRANDE DO NORTE STATE}

\begin{abstract}
Desertification has become a relevant theme in the debates about the lands' degradation, conducted by the United Nations Organization. This Organization is committed to, along with the affected countries, to combat desertification. The areas critically affected by the phenomenon in Brazil, are located in the northeastern region. The State of Rio Grande do Norte, for example, features a heavily affected area, called the Seridó Desertification Core, which comprises six municipalities. This article aims to present a literature review on the process of desertification, emphasizing the panorama of the phenomenon in the State of Rio Grande do Norte, in the Seridó region, in the northeastern region of Brazil, especially in the city of Parelhas. Thus, the article may be referred to as the basis for future studies in this area and in other places with similar characteristics.
\end{abstract}

Keywords: Environmental Degradation; Semiarid; Parelhas; Ceramics

\section{ENFOQUES SOBRE EL PROCESO DE DESERTIFICACIÓN: UNA REVISIÓN DE LAS EVIDENCIAS EN EL RIO GRANDE DO NORTE}

Resumen: La desertificación se ha convertido en un tema importante en los debates sobre la degradación de la tierra realizados por la Organización de las Naciones Unidas, que se ha comprometido a, junto a los países afectados, combatirla. Áreas críticamente afectadas por el fenómeno en Brasil están localizadas en la región noreste. La província de Rio Grande do Norte, por ejemplo, cuenta con una zona fuertemente afectada, llamada Núcleo de

\footnotetext{
${ }^{1}$ Doutora em Desenvolvimento e Meio Ambiente (DDMA/UFRN). Email: azevedo.jane2@yahoo.com.br

${ }^{2}$ Professora Titular da Universidade Federal do Rio Grande do Norte, Departamento de Geologia. Email: raquel@geologia.ufrn.br
} 
Desertificação do Seridó, que incluye seis municípios. Este artículo objetiva presentar una revisión de literatura acerca del proceso de desertificación, sobre todo el panorama del fenómeno en la província de Rio Grande do Norte en la región Noreste de Brasil, especialmente en el pueblo de Parelhas. Por lo tanto, se puede consultar el artículo como fuente en futuros estudios en la región y en otros lugares con características similares.

Palabras clave: Degradación Ambiental; Semiárido; Parelhas; Cerámica

\section{INTRODUÇÃO}

A discussão a respeito da desertificação tem ganhado força ao longo dos anos, visto que o fenômeno vem se tornando cada vez mais evidente. As regiões áridas, semiáridas e subúmidas secas são as mais vulneráveis a tal ocorrência, seja por fatores naturais ou por ação antrópica. Atualmente, os estudos a respeito da desertificação abrangem dimensões globais, pois o fenômeno atinge as chamadas regiões de terras secas de todo o planeta (ZHA; GAO, 1997; SEELY, 1998; SALES, 2002; Wu; Ci, 2002; ROSÁRIO, 2004; YANG et al, 2005; BEEKMAN, 2006, CAVALCANTE; COUTINHO; SELVA, 2007; MORAIS, 2010; NASCIMENTO, 2013).

A história do conceito de desertificação, de acordo com Matallo Jr. (1999), tem início nos anos 1930, quando intensos processos de degradação ocorreram em alguns estados do meio oeste americano. Desmatamentos e intensificação da exploração dos solos por meio da agricultura e pecuária, somados à forte seca entre os anos de 1929 e 1932, foram as causas principais do processo que ficou conhecido como Dust Bowl. Verdum et al. (2001) apontam o francês Aubreville, em 1949, como o precursor da conscientização sobre a desertificação, quando do uso do conceito para identificar o surgimento de "verdadeiros desertos" nas excolônias europeias no norte da África, nos países onde a precipitação anual varia entre 700 a $1.500 \mathrm{~mm}$.

Nesse contexto, dentre as regiões áridas, semiáridas e susceptíveis à seca, destacou-se a região do Sahel (continente africano), onde, assim como em outras regiões secas, a chuva é escassa e variável. De acordo com Hare et al. (1992), a seca atingiu severamente essa região entre 1968 e 1973. Em 1970, a precipitação anual foi de 149 mm, em 1971, foi de 126 mm e, em 1972, foi a pior seca de todas, com registro de apenas $54 \mathrm{~mm}$, uma situação típica, mas que se tornou catastrófica no ano de 1973. Houve muitas mortes e a ocorrência de grandes migrações e campos de refugiados.

Esse quadro de anos sucessivos de seca desencadeou danos sociais, ambientais e econômicos à região do Sahel. Dessa forma, a gravidade da situação na região chamou a atenção mundial,

serviu de estímulo imediato para o apelo, em 1974, da Assembléia [sic] Geral das Nações Unidas à cooperação internacional para combater a desertificação, incluindo a convocação 
de uma conferência internacional sobre a desertificação à qual seria submetido um plano de ação (HARE et. al., op. cit. p. 14).

Assim, no ano de 1977, na cidade de Nairóbi, Quênia, aconteceu a Conferência das Nações Unidas de Combate à Desertificação. Na ocasião, discutiu-se especificamente o fenômeno da desertificação e a importância de criar medidas para enfrentá-la mundialmente, suscitando, assim, um Plano de Ação Mundial de Combate à Desertificação. Desde então, outros importantes eventos aconteceram, por exemplo, a Rio-92, que resultou no documento da Agenda 21, o qual tem um capítulo dedicado à luta contra a desertificação e a seca, bem como fóruns, congressos e convenções.

No que diz respeito ao conceito de desertificação, a Organização das Nações Unidas (ONU) define como sendo "a degradação da terra nas regiões áridas, semiáridas e subúmidas secas, resultante de vários fatores, entre eles as variações climáticas e as atividades humanas" (ONU, 1994, p. 4). Essa é a definição oficial da ONU e mesmo que alguns autores apresentem conceitos generalistas, há um consenso entre as conceituações, já que estão relacionadas a fatores climáticos, à degradação do solo, da vegetação e à ação antrópica em regiões de clima árido, semiárido e subúmido seco.

Conti (2008) ressalta que a desertificação pode ser entendida, preliminarmente, como um conjunto de fenômenos que conduz determinadas áreas a se transformarem em desertos ou a eles se assemelharem. Pode, portanto, resultar de mudanças climáticas determinadas por causas naturais ou pela pressão das atividades humanas sobre ecossistemas frágeis, sendo, nesse caso, as periferias dos desertos (ou áreas transicionais) as de maior risco de degradação generalizada, em virtude de seu precário equilíbrio ambiental.

Garduño (1992) refere-se à desertificação como o empobrecimento de ecossistemas áridos e semiáridos, também de alguns úmidos, causado pelo impacto das atividades do homem. É um processo de mudança que leva à redução da produtividade, a alterações na biomassa e na diversidade das formas de vida, à degradação acelerada do solo e ao aumento dos riscos inerentes à ocupação da terra pelo homem. Assim, a desertificação é o resultado da utilização abusiva da terra.

No entanto, Matallo Jr. (2001) enfatiza que o conceito desse fenômeno aponta para algumas fragilidades teóricas. O autor, analisando o que é atualmente aceito pelas Nações Unidas, ressalta que:

A ideia de "degradação da terra" é ela mesma uma ideia complexa, com diferentes componentes. Esses componentes são: a) degradação de solos, b) degradação da vegetação, c) degradação de recursos hídricos, e d) redução da qualidade de vida da população. Esses 4 componentes dizem respeito a 4 grandes áreas de conhecimentos: físicos, biológicos, hídricos e socioeconômicos (MATALLO JR., 2001, p. 24). 
Para Cavalcanti; Coutinho; Selva (2007), essas fragilidades teóricas levam diretamente à necessidade de delineamento do objeto de estudo e da abordagem multidisciplinar requerida, que se constituem, sem dúvida, em desafios ao tradicional modelo de conhecimento presente nas instituições de ensino e pesquisa.

Nesse sentido, há diferentes aspectos que envolvem a questão da desertificação e cada um deles requer uma metodologia específica. Existe uma série de ameaças sobre o modo de vida das populações que habitam áreas susceptíveis à desertificação ou desertificadas. Isso mostra claramente que o problema também é de ordem social, econômica, política e de caráter urgente quanto à necessidade de se atuar para combatê-lo e/ou mitigá-lo. Diante disso, é necessário conhecer a realidade local das áreas a serem estudadas, para que se possa formular medidas preventivas e de conscientização pertinentes a cada situação. Este artigo tem como objetivo apresentar uma revisão de literatura do processo de desertificação, com destaque para o panorama do fenômeno no estado do Rio Grande do Norte, na região do Seridó, especialmente no município de Parelhas.

\section{AS REGIÕES SECAS E A DESERTIFICAÇÃO NO MUNDO}

As regiões secas são constituídas pelas áreas áridas, semiáridas e subúmidas secas, que estão espalhadas por todos os continentes do globo terrestre e apresentam risco de desertificação. Nessas áreas, esse fenômeno vem se instaurando devido às práticas inadequadas de uso da terra, atividades agropastoris, associadas ainda às condições climáticas desfavoráveis e secas consecutivas.

Em termos ambientais, as terras secas caracterizam-se por precipitações pouco frequentes, irregulares e imprevisíveis, grande diferença entre as temperaturas diurnas e noturnas, solos com pouca matéria orgânica e ausência de água, plantas e animais adaptados às variáveis climáticas - resistentes à seca, tolerantes à salinidade, resistente ao calor e capazes de sobreviver em condições de falta de água (UNCCD, 2012).

As terras secas, que representam quase $34 \%$ da superfície terrestre e são a principal garantia de segurança alimentar, principalmente para os mais pobres, estão se degradando diariamente; o sustento de milhões de pessoas em todo o mundo depende de pequenos agricultores (UNCCD, 2014). Esses pequenos agricultores que têm suas terras afetadas pela desertificação são obrigados a migrar para outras áreas em busca de terras produtivas e água. De acordo com Sampaio; Araújo; Sampaio (2005, p. 103), "as consequências ambientais da degradação do solo são bastante graves por si próprias, mas seu aspecto mais danoso é na redução da capacidade de produção das terras, principalmente quando esta redução é 
irreversível”. A falta de recursos tecnológicos para cultivar, as condições climáticas adversas e a falta de acesso a parcelas maiores de terras contribuem também para o aumento de áreas em processo de desertificação.

Quanto à desertificação no mundo, as principais regiões atingidas são a porção ocidental da América do Sul e dos Estados Unidos, a Austrália, a porção centro meridional da Eurásia, o norte-nordeste e o sul do continente africano. Para exemplificar, em Portugal, 36\% da área continental está incluída em condições de susceptibilidade à desertificação; dos restantes $64 \%$, há também um número significativo de áreas que, apesar de diferentes condições climáticas, apresentam solos com elevada a muito elevada susceptibilidade à seca e à desertificação (ROSÁRIO, 2004).

Na Namíbia, a seca é uma característica recorrente do clima e a desertificação é um problema nacional grave (UNFCCC, 2002). De acordo com Seely (1998), 34\% da Namíbia é árida, $58 \%$ é semiárida e apenas $8 \%$ pode ser classificado como subúmido seco. O autor enfatiza, ainda, que para combater a desertificação e fornecer soluções viáveis para amenizar a degradação da terra é necessária a participação da comunidade local e da ciência para juntos compartilharem conhecimento e atuarem a favor de um ambiente menos degradado.

Conforme Lu; Wang (2003), a China, em termos de gravidade da desertificação, possui, da área total de terras degradadas, 20\% ligeiramente desertificada, 33\% moderadamente desertificada, $21 \%$ muito desertificada e $26 \%$ seriamente desertificada. No ano de 1970, a desertificação teve uma taxa anual de expansão de $1.560 \mathrm{~km}^{2}$, em 1980, foram $2.460 \mathrm{~km}^{2}$ e, em meados da década de 1990, foram $3.436 \mathrm{~km}^{2}$.

Outros estudos desenvolvidos na China (ZHA; GAO, 1997; WU; CI, 2002; YANG et $a l ., 2005)$ assinalaram o aumento da desertificação especialmente nas regiões de clima árido e semiárido do país. Destacaram que as condições naturais adversas (clima, solo, vegetação) e as atividades humanas (agricultura, pecuária, corte de lenha e de espécies vegetais medicinais) são responsáveis pela expansão das áreas desertificadas, tendo em vista que estão intrinsecamente ligadas.

A princípio, as abordagens internacionais sobre desertificação estiveram exclusivamente associadas à incidência de fatores naturais e antrópicos. Contudo, ao longo dos anos, essas abordagens estão sendo aprimoradas, levando-se em consideração aspectos sociais, políticos, econômicos e culturais, isto é, os estudos do fenômeno ganharam novos olhares, novas metodologias e planejamentos conjuntos por parte das nações afetadas. Um exemplo disso é a formulação de sistemas e metodologias de indicadores da desertificação. Segundo Matallo Jr. (2001, op. cit.), o esforço que vem sendo feito na América Latina e no 
Caribe para o desenvolvimento de metodologias menos padronizadoras (em relação às metodologias existentes em outros continentes) e voltadas para sistemas de indicadores da desertificação é muito significativo.

No continente sul-americano, está sendo implementado o Programa de Combate à Desertificação e Mitigação dos Efeitos da Seca, com o objetivo de elaborar uma base sólida para a identificação de zonas áridas degradadas e secas na Argentina, no Brasil, na Bolívia, no Chile, no Equador e no Peru, de acordo com os princípios da Convenção das Nações Unidas de Combate à Desertificação. Para isso, políticos, técnicos e cientistas reuniram-se com o propósito de formular indicadores comuns a serem usados em escala regional para medir os processos de desertificação. Assim, no ano de 2006, foi lançado o livro Indicadores de la Desertificación para América Del Sur: Recopilación y armonización de indicadores y puntos de referencia de la desertificación a ser utilizados em el programa Combate a la desertificación y mitigación de los efectos de la sequía en América del Sur.

Fazem parte do programa supracitado seis países: Argentina, Bolívia, Brasil, Chile, Equador e Peru. De acordo com Beekman (2006), aproximadamente 15\% das terras do Brasil são semiáridas, das quais grandes porções estão sujeitas ao processo de degradação. Na Argentina, 70\% do território continental está sujeito à desertificação. No que diz respeito à Bolívia, aproximadamente $41 \%$ das terras encontram-se afetadas. Já no Chile, as áreas consideradas vulneráveis representam cerca de $45 \%$ da superfície terrestre nacional. No Equador, as áreas geográficas degradadas são relativamente pequenas, mas significativas em termos de população afetada. Por fim, no Peru, cerca de $22 \%$ das terras são vulneráveis à desertificação.

Esse quadro ambiental é preocupante e requer empenho da sociedade civil e das autoridades competentes. Embora algumas medidas estejam sendo tomadas para a reversão, é fundamental acompanhar, fiscalizar e monitorar essas ações, seja a nível local, regional e/ou mundial.

Diante disso, as proposições para a mitigação dos efeitos da seca e da desertificação requerem cooperação internacional. As trocas de informações e experiências ajudam os países a melhorar suas políticas de combate, tornando-as mais eficientes. Aumentar o conhecimento da população local sobre os agentes causadores da desertificação e incluí-los na luta contra seus efeitos é essencial, uma vez que "a proximidade das pessoas com os ambientes naturais propicia o desenvolvimento de relações íntimas entre os seres humanos e os recursos naturais disponíveis, dando a estas pessoas conhecimentos específicos sobre o meio ambiente no qual vivem" (SIEBER; MEDEIROS; ALBUQUERQUE, 2010, p. 02). 


\section{A DESERTIFICAÇÃO NO BRASIL}

O processo da desertificação passou a ser estudado no Brasil na década de 1970. A maioria dos estudiosos da matéria concorda com as proposições da Convenção das Nações Unidas de Combate à Desertificação a respeito dos fatores determinantes desse fenômeno, isto é, que é resultante de vários fatores, incluindo variações climáticas e atividades humanas (BRASIL, 2005b).

O precursor dos estudos da desertificação em nosso país foi o professor João Vasconcelos Sobrinho, da Universidade Federal Rural de Pernambuco. Conforme Sales (2002), os primeiros trabalhos nos quais aparece o conceito de desertificação como degradação das terras produtivas no semiárido foram conduzidos na região Nordeste pelo professor e, sem dúvida alguma, deve-se a esse pesquisador o mérito do pioneirismo nesses estudos.

Na concepção de Vasconcelos Sobrinho, desertificação é o processo de degradação dos ecossistemas por causas naturais ou pela ação do homem, ou por ambas conjugadas, tornando as áreas onde ocorre impróprias para a ocupação humana e podendo conduzir à formação de desertos. Para ele, são nas terras áridas e semiáridas e nas marginais subúmidas onde se produz a desertificação, cujas causas são necessárias determinar. O autor destacou também que a humanidade ainda não se conscientizou do perigo do fenômeno, que existe o processo no Brasil e que é amplo e grave, já sendo possível encontrar núcleos de desertificação (FUNDAÇÃO VINGT-UN ROSADO, 1990).

As áreas afetadas e/ou susceptíveis à desertificação no Brasil encontram-se, predominantemente, na região semiárida, e as consideradas em estágio mais avançado estão situadas no Nordeste. De acordo com o Instituto Nacional do Semiárido - INSA (2012), o espaço geográfico do semiárido brasileiro estende-se por oito estados da região Nordeste (Alagoas, Bahia, Ceará, Paraíba, Pernambuco, Piauí, Rio Grande do Norte e Sergipe), além do norte de Minas Gerais, totalizando uma extensão territorial de $980.133,079 \mathrm{~km}^{2}$. A população residente no semiárido brasileiro alcançou a marca de 22.598 .318 habitantes em 2010, representando $11,85 \%$ da população brasileira, $42,57 \%$ da população nordestina, $28,12 \%$ da população residente na região Sudeste.

Na região Nordeste, o processo de desertificação evidencia-se na porção semiárida, em uma área aproximada de $788.064 \mathrm{~km}^{2}$ ou $48 \%$ da região. Desse total, Paraíba, Bahia e Ceará são os mais afetados; esse último, por exemplo, detém $136.328 \mathrm{~km}^{2}$ de áreas semiáridas 
suscetíveis à desertificação. O Ceará tem 92,1\% de seu território distribuído no perímetro da semiaridez, ou seja, a maior área proporcional do Nordeste seco (NASCIMENTO, 2013).

O Brasil, cumprindo seus compromissos como país signatário da Convenção das Nações Unidas de Combate à Desertificação, elaborou o Programa de Ação Nacional de Combate à Desertificação e Mitigação dos Efeitos da Seca - PAN/Brasil. "O espaço objeto da atuação do PAN/Brasil é caracterizado como Áreas Susceptíveis à Desertificação - ASD” (BRASIL, 2005b, op. cit. p. 14). Dessa forma, as ASD “compreendem $1.340 .863 \mathrm{~km}^{2}$, abraçando 1.488 municípios de nove estados da região Nordeste, além de alguns municípios setentrionais dos estados de Minas Gerais e Espírito Santo” (PEREZ-MARIN et al., 2012, p. $88)$.

Assim, há áreas nos estados do Maranhão e Espírito Santo onde as características ambientais, hoje vislumbradas, sugerem a ocorrência de processos de degradação tendentes a transformá-las em áreas também sujeitas à desertificação, caso não sejam adotadas medidas de preservação e conservação ambiental (BRASIL, 2005b, op. cit.). Essas áreas são consideradas como áreas do entorno, pois apresentam características comuns às semiáridas e subúmidas secas (ocorrência de secas e enclaves da vegetação caatinga).

De acordo com o Atlas das Áreas Suscetíveis à Desertificação do Brasil, as ASD foram determinadas seguindo os pressupostos norteadores da Convenção das Nações Unidas de Combate à Desertificação, que propõem a adoção do Índice de Aridez (IA), base da classificação climática de Thornthwaite, de 1941, sendo calculado pela razão entre a precipitação pluviométrica e a evapotranspiração. De acordo com esse índice, quando a razão estiver entre 0,05 e 0,20, o clima é considerado árido; na faixa entre 0,21 e 0,50, o clima é caracterizado como semiárido; quando estiver entre 0,51 e 0,65, considera-se subúmido seco e, por fim, acima desse valor, subúmido úmido ou úmido (BRASIL, 2007). Foram estabelecidas três categorias de susceptibilidade à desertificação em conformidade com o IA, sendo estas: muito alta (de 0,05 até 0,20), alta (de 0,21 até 0,50) e moderada (de 0,51 até 0,65) (MATALLO JR., 1999, op. cit.).

Nas ASD, as práticas agrícolas insustentáveis, a pecuária, o corte de lenha, a retirada de argila, entre outras contribuem sobremaneira para intensificar a degradação nessas áreas. Nos locais onde a degradação é maior, estão os núcleos de desertificação. Segundo PerezMarin et al. (op. cit.), o ecólogo João Vasconcelos Sobrinho apresentou as primeiras ideias sobre os Núcleos de Desertificação em 1971, na obra intitulada Núcleos de Desertificação no polígono das secas. Com a colaboração do professor Vasconcelos Sobrinho, foi realizado um estudo com o objetivo de identificar as áreas mais atingidas pelo fenômeno e as mais críticas. 
Foram selecionadas seis áreas consideradas núcleos de desertificação ou áreas piloto. Tais áreas estão nos estados do Piauí (Área piloto 1 - Núcleo de Gilbués), Ceará (Área piloto 2 - Núcleo de Irauçuba), Rio Grande do Norte (Área piloto 3 - Núcleo do Seridó), Paraíba (Área piloto 4 - Núcleo Cariris Velhos), Pernambuco (Área piloto 5 - Núcleo de Cabrobó) e Bahia (Área piloto 6 - Núcleo do Sertão de São Francisco). Os núcleos de Gilbués, Irauçuba, Seridó e Cabrobó foram caracterizados como de alto risco à desertificação (BRASIL, 2005b, op. cit.).

$\mathrm{Na}$ tentativa de hierarquizar os níveis de gravidade dos processos nas áreas afetadas pelo fenômeno, foi formulada uma metodologia de estudo de indicadores de desertificação pelo Instituto Desert, “organização não governamental que, ao longo de sua existência, contribuiu de forma pioneira para as discussões ligadas à desertificação no Brasil; foi formada por professores da Universidade Federal do Piauí” (PIAUÍ, 2005, p. 11).

Foram utilizados 19 indicadores para representar os componentes físicos, biológicos e socioeconômicos. Com base na aplicação dos indicadores, classificam-se as áreas desertificadas em: muito grave (15 a 19 indicadores), grave (11 a 14 indicadores) ou moderada (6 a 10 indicadores). Apesar de tal metodologia ter sido questionada e necessite de aprimoramentos, sua contribuição deve ser reconhecida, afirma Matallo Jr. (2001, op. cit.).

\section{O QUADRO DA DESERTIFICAÇÃO NO RIO GRANDE DO NORTE}

O estado do Rio Grande do Norte abrange uma área de $52.811 .047 \mathrm{~km}^{2}$, com 167 municípios e população de 3.168.027 habitantes, sendo 2.464.991 na zona urbana e 703.036 na zona rural (IBGE, 2010a). As economias fundadoras do estado foram a cana-de-açúcar, no litoral (primeira atividade econômica que serviu de base para o povoamento), a pecuária, da qual surgiram as primeiras fazendas de criatório implantadas no sertão, no início do século XVIII, e a economia algodoeira no espaço sertanejo, que foi objeto de exportação (FELIPE; ROCHA; CARVALHO, 2011).

No que se refere às condições climáticas, o Rio Grande do Norte caracteriza-se por apresentar temperatura média anual em torno de $25,5^{\circ} \mathrm{C}$, com máxima de $31,3^{\circ} \mathrm{C}$ e mínima de $21,1^{\circ} \mathrm{C}$, pluviometria bastante irregular (em termos de quantidade e período), e umidade relativa do ar com variação média anual de 59\% a 76\%. Em decorrência de sua localização geográfica próxima ao Equador, predominam as elevadas temperaturas, verificando-se entre 2.400 e 2.700 horas por ano de insolação (RIO GRANDE DO NORTE, 2005a).

A maior parte do território potiguar está inserida na porção semiárida, onde as temperaturas elevadas e a irregularidade pluviométrica no tempo e no espaço são marcantes. 
Apresenta " $88,02 \%$ de seus municípios inseridos na porção semiárida, esse percentual corresponde a 147 municípios dos 167 existentes no estado" (INSA, op. cit. p. 31). Nesse espaço semiárido, a caatinga é a vegetação predominante, e o seu uso intenso tem devastado hectares de terras por todo o estado, contribuindo para o desgaste e a degradação do solo.

No Rio Grande do Norte, as Áreas Susceptíveis à Desertificação (ASD), ou seja, aquelas onde o processo pode vir a ocorrer, equivalem a 95,21\%, compreendendo 159 municípios dos 167 existentes. Desses municípios, 143 integram a área semiárida, 13 fazem parte da área subúmida seca e 3 compõem a área do entorno (RIO GRANDE DO NORTE, 2010).

Na parte semiárida do estado, concentra-se um número significativo de indústrias de cerâmica vermelha, atividade apontada como responsável por um sério quadro de degradação ambiental, considerando o consumo de lenha e argila. De acordo com o Serviço de Apoio às Micro e Pequenas Empresas do Rio Grande do Norte, no setor cerâmico do RN existem 186 cerâmicas em atividade, e destas 179 consomem exclusivamente lenha, sendo o consumo mensal de $102.843 \mathrm{~m}^{3}$, correspondendo a um consumo anual de $1.234 .116 \mathrm{~m}^{3}$. No que diz respeito ao consumo mensal de argila nas 186 cerâmicas, este é de 239.561 toneladas (SEBRAE/RN, 2013).

$\mathrm{Na}$ tentativa de amenizar o quadro ambiental existente e colaborando com as proposições mundiais de combate à desertificação, o estado do Rio Grande do Norte elaborou o Programa de Ação Estadual de Combate à Desertificação e Mitigação dos Efeitos da Seca do Rio Grande do Norte (PAE/RN). Nas fases de elaboração, foram feitos diagnósticos analíticos e escuta à sociedade, constituindo-se um instrumento de informações a respeito do quadro de desertificação no estado. O processo de construção foi coordenado pelo governo estadual, por meio da Secretaria do Meio Ambiente e dos Recursos Hídricos - SEMARH e de parceiros.

A problemática da desertificação no estado vem sendo cada vez mais tema de estudos na área. O estudo de Bezerra et al. (2011) analisou e identificou, por meio da técnica de espacialização, áreas propícias ao processo de degradação ambiental que resultam na desertificação. Percebeu-se que a região semiárida do RN está sendo afetada por processos tanto da ação de fatores naturais quanto da ação antrópica. De acordo com os resultados da pesquisa, os municípios mais propícios aos processos de desertificação são os localizados nas microrregiões de Angicos, Agreste Potiguar, Baixa Verde, Borborema Potiguar, Macau, Mossoró, Médio Oeste, Serra de Santana, além do Seridó Ocidental e Seridó Oriental, os quais são os mais impactados. 
Maia; Costa (2011) realizaram um estudo em dois municípios (Francisco Dantas e Encanto) na mesorregião Oeste Potiguar, aplicando o Sistema Básico de Indicadores para a Identificação e Monitoramento dos Processos de Desertificação na América Latina e Caribe, proposto por Matallo Jr. Dessa forma, o sistema mostrou-se eficaz em apontar indícios do processo de desertificação nos dois municípios estudados, causados não apenas por fatores climáticos, mas também por atividades antrópicas.

Szilagyi (2007) procurou diagnosticar o atual quadro da desertificação no município de Lajes, localizado na região Central do RN, utilizando métodos quantitativos, construção dos balanços hídricos e índices de aridez do município. Pode-se, com isso, ratificar a classificação do município como pertencente a uma área de alta susceptibilidade à desertificação, em nível grave na classe de intensidade do fenômeno.

De acordo com o estudo de Morais et al. (2010), a cartografia da desertificação no Rio Grande do Norte referenda a correlação estabelecida entre o fenômeno e a área do ecossistema da caatinga, ou seja, sob o domínio do semiárido. Tem-se um quadro em que apenas a microrregião do Litoral Sul, ou seja, 2,4\% da superfície potiguar, não demonstra susceptibilidade à desertificação. No outro extremo, situa-se a região do Seridó, onde o nível intenso de degradação da terra conferiu o reconhecimento da existência de um núcleo de desertificação.

\section{A REGIÃO DO SERIDÓ POTIGUAR}

A região do Seridó está localizada na Mesorregião Central Potiguar, sendo composta por duas microrregiões, Seridó Ocidental (7 municípios) e Seridó Oriental (10 municípios). Juntos, esses 17 municípios possuem população de aproximadamente 215.896 habitantes, de acordo com o censo de 2010 do Instituto Brasileiro de Geografia e Estatística (IBGE). Macêdo (2012) enfatiza que, historicamente, o Seridó se constituiu sob a economia pecuarista. Ostensivamente, foram as atividades pastoris que moldaram a história seridoense, de forma quase absoluta, até o final do século XIX.

A partir do século XX, mudanças começaram a surgir na região, por exemplo, nos contingentes populacional e econômico. Os espaços urbanos foram se ampliando, bem como o setor terciário. Desse modo,

estabeleceu-se a coexistência entre antigas e novas economias, destacando-se a produção ceramista que obteve significativo crescimento, apesar de ser extremamente danosa ao meio ambiente. Além disso, as cidades se expandiram e se multiplicaram, estradas foram construídas e muitas alterações foram impressas ao espaço. Neste processo, elevaram-se as demandas em relação aos recursos naturais, mas também foram ampliadas as possibilidades de intervenção do homem no espaço empregando-se tecnologias. Todavia, já são notáveis os sinais de descompasso entre os recursos naturais disponíveis e o atendimento as demandas sociais (MORAIS, op. cit. p. 75). 
Identifica-se que as principais atividades econômicas da região Seridó são causadoras de um quadro ambiental crítico, sendo consideradas como primícias da degradação na região a pecuária e a cotonicultura. Atualmente, as atividades de base mineral, com destaque para a cerâmica vermelha, vêm agravando ainda mais esse quadro. "A extração de argila de solos de aluviais, tendo como destino a produção ceramista, foi apontada como causa principal da desertificação" (RIO GRANDE DO NORTE, 2010, op. cit., p. 31).

No entanto, a retirada da vegetação para abastecer os fornos não só das cerâmicas, como também das indústrias de panificação, caieiras, carvoarias, queijeiras, entre outros, contribui para o avanço da degradação na região, haja vista que "o conjunto dessas atividades explora da natureza a sua principal fonte energética - lenha, de maneira indiscriminada" (ADESE, 2008, não paginado).

O setor ceramista teve um crescimento significativo a partir da década de 1980. De acordo com Rio Grande do Norte (2005b, op. cit.), em 1980, as estatísticas sobre a região do Seridó registravam apenas 8 unidades de produção de telhas e tijolos, utilizando-se de um processo de produção artesanal. No ano 2000, contava-se com 71 cerâmicas. Em 2007, de acordo com a Agência de Desenvolvimento Sustentável do Seridó (ADESE), o número de cerâmicas era de 82 unidades fabris.

No ano de 2013, a região do Seridó possuía 99 cerâmicas em atividade, que correspondem a $53 \%$ do número de unidades no Rio Grande do Norte, concentra o maior número de cerâmicas e produz $57 \%$ do total de peças cerâmicas do estado (SEBRAE/RN, op. cit.). A expansão da indústria de cerâmica vermelha aumentou a demanda por matéria-prima, argila e o uso energético da lenha, contribuindo para o surgimento de áreas em processo de degradação.

O consumo mensal de argila na região do Seridó em 2013 correspondeu a 100.576 toneladas, o equivalente a $42 \%$ do consumo de argila do RN para a atividade. Parte dessa argila é proveniente do estado da Paraíba, várzeas de rios do $\mathrm{RN}$, barragens e açudes, conforme SEBRAE/RN (op. cit.); além disso, as cerâmicas necessitam usar combustíveis florestais para a queima de seus produtos. No Seridó, o recurso mais utilizado é a lenha, o que é grave, já que colabora para um desmatamento sistemático na região. O consumo médio de lenha na região, com base no consumo médio dos fornos e na produção média da região, é de $46.314 \mathrm{~m}^{3}$ (SEBRAE/RN, op. cit.).

A atividade ceramista é responsável pela mudança significativa da economia na região, bem como pela geração de vários de empregos diretos e indiretos. Por outro lado, a 
demanda de recursos naturais que esse tipo de atividade requer pode estar contribuindo para o desgaste dos recursos naturais em uma área onde se encontra um dos seis núcleos de desertificação existentes no Nordeste brasileiro, reconhecido pelo Ministério do Meio Ambiente.

\section{O NÚCLEO DE DESERTIFICAÇÃO DO SERIDÓ}

As primeiras referências sobre a formação de núcleos de desertificação no Brasil, mais especificamente no Nordeste, foram pioneiramente apresentadas pelo professor Vasconcelos Sobrinho. O estudo do autor foi o primeiro a indicar o Seridó norte-rio-grandense como núcleo de desertificação (RIO GRANDE DO NORTE, 2005a op. cit.).

O estudo do Panorama da Desertificação do estado do Rio Grande do Norte ressalta que os núcleos de desertificação apresentam um dinamismo próprio, com tendência à expansão em detrimento de áreas vizinhas caso se agucem os processos desencadeadores de sua formação. Estes,

são redutos onde a degradação ambiental é maximizada e os efeitos da conjugação de variáveis naturais e humanas se evidenciam de forma clara, deixando transparecer no espaço a deterioração das relações socioambientais (RIO GRANDE DO NORTE, 2005a, op. cit., p. 53).

O Núcleo de Desertificação do Seridó ocupa 2.792.418 km² do território potiguar (RIO GRANDE DO NORTE, 2010 op. cit.). Seis municípios compõem essa área: Acari, Carnaúba do Dantas, Cruzeta, Currais Novos, Equador e Parelhas. Esses municípios, exceto Equador, fazem parte do Polo Cerâmico do Seridó, e as práticas inadequadas da agricultura, da pecuária e do cultivo de algodão cooperaram para um quadro ambiental bastante fragilizado nesses locais. Atualmente, as atividades de base mineral, sobretudo a cerâmica, estão incrementando ainda mais esse quadro, devido ao consumo de lenha e argila (ADESE, 2008; RIO GRANDE DO NORTE, 2010).

Dos seis municípios pertencentes ao Núcleo de Desertificação do Seridó, Parelhas foi escolhido para a implantação da primeira área piloto do Núcleo de Desenvolvimento Sustentável (NUDES), criado pelo Ministério Público do RN para atuar junto a instituições governamentais e não governamentais, associações comunitárias e à população local em geral por um ambiente mais sustentável. A área de atuação do NUDES abrange as comunidades rurais Juazeiro, Santo Antônio da Cobra e Cachoeira. A escolha da área justifica-se pela localização das comunidades, às margens do rio Cobra, pelo desmatamento existente em 
decorrência da atividade ceramista presente nelas, entre outros (RIO GRANDE DO NORTE, 2005b, op. cit.).

\section{O MUNICÍPIO DE PARELHAS}

O município de Parelhas (Figura 1) está localizado na porção centro-sul do RN, na microrregião do Seridó Oriental, distante $240 \mathrm{~km}$ da capital Natal. É a terceira maior cidade da região do Seridó, com uma população de 20.354 habitantes, sendo 17.084 na zona urbana e 3.270 na zona rural, e possui uma área territorial municipal de $513 \mathrm{~km}^{2}$ (IBGE, 2010b). Apresenta características econômicas, sociais e naturais semelhantes aos demais municípios da região do Seridó, como também intensa degradação de recursos naturais.

Figura 1: Localização do município de Parelhas/RN

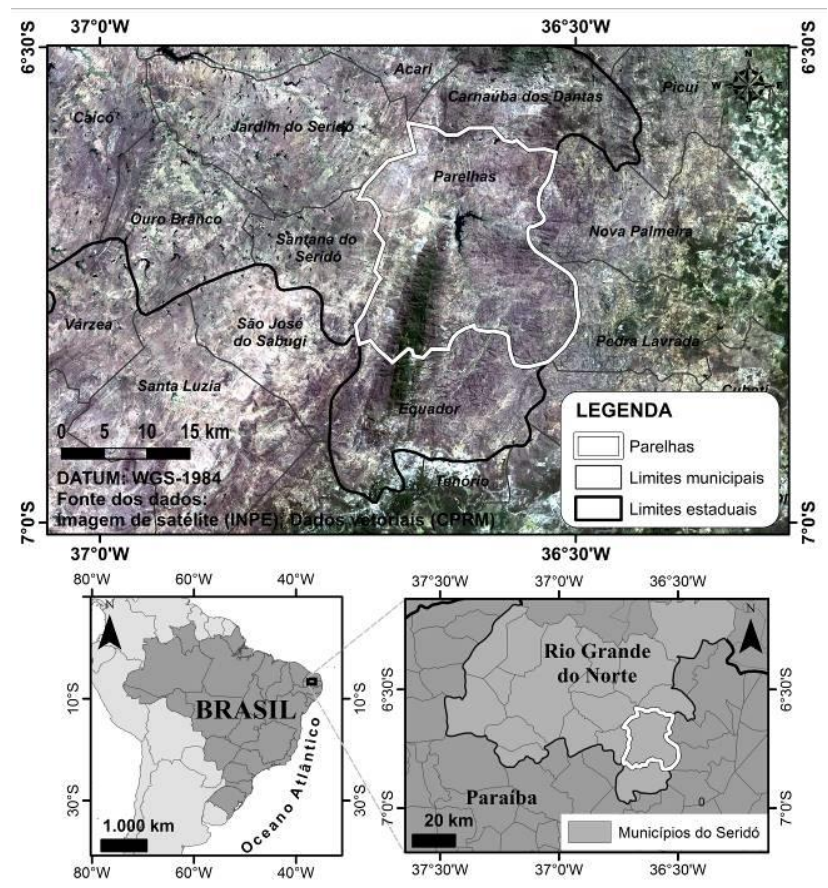

Fonte: elaborado por Robson Rafael de Oliveira

A caatinga é a vegetação predominante no município e o clima é semiárido. Os solos são pedregosos, do tipo "neossolos litólicos e luvissolos crômicos” (IBGE, 2007, p. 231). As formações geológicas consistem em rochas cristalinas, sendo formadas por rochas resistentes como granitos, quartzitos, gnaisses e micaxistos (FELIPE; CARVALHO; ROCHA, 2011).

A população concentra-se, em sua maioria, no espaço urbano. A migração da população rural para a cidade aumentou a partir da década de 1990; assim, "um dos aspectos relevantes na análise da evolução da população de Parelhas é o acelerado declínio de sua população 
rural, esse associado à instabilidade da economia agrícola, às secas periódicas e ao processo de desertificação" (TRAJANO, 2005, p. 95).

A vida econômica, social e política foi estruturada com base nos princípios básicos: pecuária-algodão-extração mineral. Com o declínio da exploração da cultura algodoeira nas décadas de 1980 e 1990, as populações envolvidas nos processos anteriormente descritos buscaram novas alternativas para geração de renda e consequente sobrevivência no ambiente semiárido seridoense. Verifica-se, então, no município de Parelhas, uma nítida expansão da indústria cerâmica (RIO GRANDE DO NORTE, 2005b, op. cit.).

Parelhas destaca-se como o maior produtor de telha da região. Segundo o SEBRAE/RN (2013), das 99 cerâmicas existentes na região Seridó, o município possuía 33 em atividade. Algumas dessas cerâmicas estão localizadas na zona rural, por exemplo, nas comunidades Cachoeira, Juazeiro e Santo Antônio da Cobra, entre outras localidades.

Nascimento (2011) constatou que no ano de 2010 havia 30 cerâmicas funcionando no município, fabricando telhas, tijolos e lajotas na quantidade de 18.690 milheiros/mês, empregando cerca de 1.060 pessoas e consumindo 11.488 metros estéreos de lenha por mês (Tabela 1).

Tabela 1: Evolução do consumo da lenha na indústria ceramista

\begin{tabular}{c|c|c|c|c|c}
\hline \multicolumn{2}{c|}{ Rio Grande do Norte } & \multicolumn{2}{|c|}{ Região Seridó } & \multicolumn{2}{c}{ Parelhas/RN } \\
\hline $\begin{array}{c}\mathrm{N}^{\circ} \text { de } \\
\text { Cerâmicas }\end{array}$ & $\begin{array}{c}\text { Consumo } \\
\text { mensal } \\
\text { de lenha } \\
\mathrm{em} \mathrm{m}^{3}\end{array}$ & $\begin{array}{c}\text { Número } \\
\text { de } \\
\text { Cerâmicas }\end{array}$ & $\begin{array}{c}\text { Consumo } \\
\text { mensal } \\
\text { de lenha } \\
\mathrm{em} \mathrm{m}^{3}\end{array}$ & $\begin{array}{c}\text { Número } \\
\text { de } \\
\text { Cerâmicas }\end{array}$ & $\begin{array}{c}\text { Consumo } \\
\text { mensal } \\
\text { de lenha } \\
\mathrm{em} \mathrm{m}^{3}\end{array}$ \\
\hline- & - & $82^{\mathrm{a}}$ & $22.749^{\mathrm{a}}$ & $28^{\mathrm{a}}$ & $7.552^{\mathrm{a}}$ \\
\hline- & - & $87^{\mathrm{b}}$ & $31.170^{\mathrm{b}}$ & $30^{\mathrm{b}}$ & $11.488^{\mathrm{b}}$ \\
\hline $186^{\mathrm{c}}$ & $102.843^{\mathrm{c}}$ & $99^{\mathrm{c}}$ & $46.314^{\mathrm{c}}$ & $33^{\mathrm{c}}$ & - \\
\hline- & - & - & - & $26^{\mathrm{d}}$ & $8.558^{\mathrm{d}}$ \\
\hline
\end{tabular}

a) ADESE (2008) - pesquisa de campo de 2007; b) NASCIMENTO (2011) - pesquisa de campo de 2010; c) SEBRAE/RN (2013) - pesquisa de campo entre novembro de 2011 e março de 2012; d) dados de campo dessa pesquisa, junho/julho (2014). Fonte: elaborado pelas autoras.

A tabela 1 mostra a evolução do consumo da lenha no município de Parelhas, bem como na região Seridó. De acordo com os dados, nesses dois lugares, o consumo da lenha aumentou significativamente em um período de cinco anos, passando de 22.749 metros estéreos em 2007 para 46.314 em 2012. Esses dados são preocupantes, pois mostram um aumento no consumo das espécies vegetais em uma área susceptível à desertificação. Isso se deve ao surgimento de novas cerâmicas que têm crescimento progressivo. Vale salientar que 
existem outras atividades (panificadoras, docerias, uso doméstico, entre outros) que utilizam a lenha como fonte energética; todavia a cerâmica tem consumo maior (ADESE, 2008; LIMA; LIMA, 2009).

Assim como na região do Seridó, a atividade ceramista tem dinamizado a economia e fornecido empregos no município de Parelhas, mas, por outro lado, pode estar contribuindo para o aumento da degradação e de áreas susceptíveis ao processo de desertificação. Acrescenta-se ainda ao uso da lenha (Figura 2) a utilização da argila (Figura 3), matéria-prima primordial para a confecção das peças cerâmicas vermelhas, que esgota os depósitos aluviais do município, de outros municípios vizinhos e até do estado da Paraíba, com destaque para “Açude Itans (Caicó/RN), Açude Gargalheiras (Acari/RN - Comunidade Bulhões) e Taperoá, município da Paraíba” (NASCIMENTO, 2011 op. cit. p. 58).

Figura 2: Pilha de lenha em pátio de cerâmica no município de Parelhas/RN

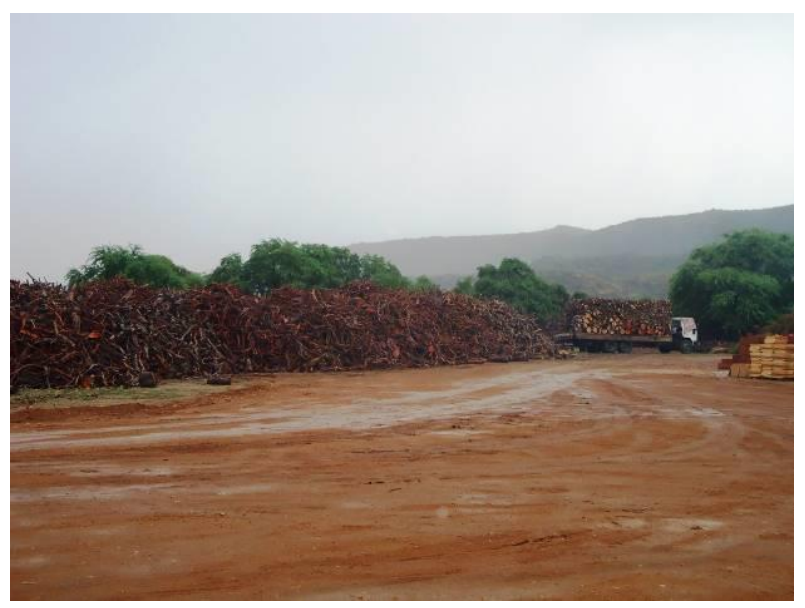

Fonte: Acervo das autoras

Figura 3: Argila disposta em pátio de cerâmica no município de parelhas/RN

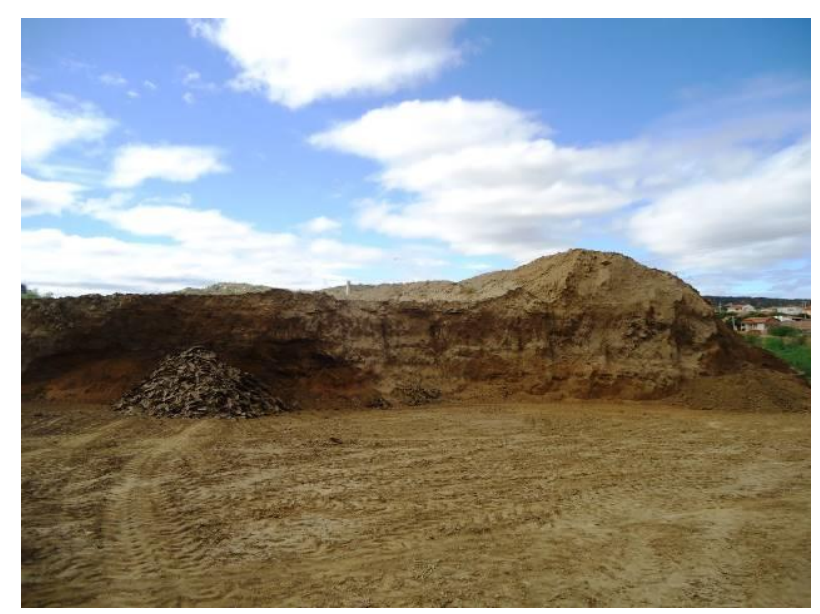

Fonte: Acervo das autoras 
A água consiste em outro recurso importante no processo de fabricação dos artefatos cerâmicos. Após o seu acréscimo à argila, esta pode ser transformada em telhas, tijolos e lajotas. A demanda por água para as indústrias de cerâmica vermelha e para o abastecimento humano e animal é expressiva, e a aquisição desta torna-se ainda mais difícil em anos consecutivos de secas, em virtude do baixo nível dos reservatórios municipais. Outrossim, a fumaça emitida das chaminés dos fornos, além de contribuir para o aquecimento global, pode afastar "várias espécies de aves e insetos que habitavam o local causando desequilíbrio ambiental" (NASCIMENTO, 2011 op. cit. p. 107). A autora cita, ainda, o abandono das colmeias das abelhas Jandaíra, fonte de renda para alguns pequenos produtores rurais.

A despeito dos efeitos da atividade ceramista em Parelhas, os resultados do estudo de Cosme Júnior (2011) indicaram que no município há um declínio nas áreas de solo exposto em 11,6\%, entre os anos de 1990 e 2010, devido ao comportamento da precipitação pluviométrica. Entretanto, as porções oeste e sudeste do município apresentaram áreas em que a cobertura da vegetação não se recuperou devido à extração de lenha para abastecer os fornos das indústrias.

O estudo de Araújo (2012) mostrou a percepção dos moradores de quatro comunidades rurais parelhenses sobre mudanças na paisagem; 70\% dos entrevistados perceberam mudanças na paisagem local nos últimos 20 anos, admitindo que houve modificações na vegetação, no solo e, até mesmo, nos corpos hídricos, ocasionando transformação na fisionomia do lugar.

Conforme mencionado, existe um quadro ambiental sério na região do Seridó, especialmente em Parelhas, que detém o maior número de indústrias do ramo ceramista em atividade. À medida que a atividade gera empregos e dinamiza a economia local, coopera para a exaustão dos recursos naturais (lenha, argila e água), o que pode contribuir para aumentar as áreas susceptíveis ao processo de desertificação. Urge, então, conscientizar a população e os empresários acerca da adesão às práticas de uso sustentável desses recursos e implementar novas políticas públicas voltadas para a gestão e o manejo adequado do uso do solo, da vegetação e da água.

\section{IMPLICAÇÕES PARA PESQUISADORES E GESTORES}

Verifica-se que as práticas efetivas de combate e controle visando mitigar efeitos do processo de desertificação são fundamentais. Medidas precisam ser tomadas, ponderadas e socializadas para despertar maior interesse da população atingida e das autoridades competentes, seja a nível mundial, regional e/ou local. 
Faz-se necessário contar com o apoio da comunidade científica intervindo com seus estudos, suas proposições sustentáveis e a criação de novas tecnologias, a fim de amenizar os efeitos nocivos da desertificação. Vale salientar que é possível agregar conhecimentos unindo o saber científico ao da comunidade local atingida, os quais, de maneira unificada, podem mudar a situação daqueles que residem em áreas afetadas e/ou susceptíveis à desertificação. A população local tem papel fundamental, pois é capaz de descrever a realidade que a cerca, detalhando as práticas de uso do solo e as demais desenvolvidas ao longo dos anos.

Por meio de entrevistas, reuniões dialogadas, rodas de conversa, o público alvo tem a oportunidade de falar e ser ouvido. A partir de seus relatos, podem-se compreender as formas de uso da terra, os fatores que ocasionaram a degradação do solo e as medidas tomadas frente ao desgaste do solo. Outro fator importante é o conhecimento da cultura local, uma vez que esta tem influência expressiva na maneira como as pessoas vivem e agem. Dessa forma, os relatos da população permitem o conhecimento da realidade local, os quais associados ao saber científico podem suscitar medidas de combate e controle à desertificação, ponderando as soluções que melhor se adaptarem. Os estudos que dizem respeito à desertificação não devem abordar apenas fatores naturais e antrópicos; outros aspectos são indispensáveis, tais como culturais, sociais, políticos, econômicos.

As trocas de experiência, sejam essas positivas (aquelas que deram certo) ou negativas (aquelas que não deram certo), podem também contribuir sobremaneira para o combate ao fenômeno. As experiências positivas de uma região, quando compartilhadas, oportunizam a aplicação de novas metodologias em outros locais, desde que analisadas e adaptadas à realidade de cada lugar. Quanto às experiências negativas, estas devem ser discutidas, reavaliadas e aperfeiçoadas a partir do ponto em que não deram certo.

A luta contra a desertificação deve se dar de forma continuada e requer compromisso real com a causa. O Brasil iniciou na década de 1970 suas discussões sobre essa questão e, apesar dos esforços envidados através de diversas ações e estudos, há ainda muitos desafios a serem enfrentados, especialmente no Nordeste, onde o fenômeno é mais expressivo. O combate à desertificação não dever ser confundido com as políticas públicas de combate à seca instauradas no semiárido brasileiro; são políticas distintas, embora interligadas, pois a seca pode contribuir, a longo prazo, para o surgimento de áreas susceptíveis à desertificação.

\section{CONSIDERAÇÕES FINAIS}

Conclui-se, desse modo, que a desertificação se tornou tema relevante nos debates internacionais sobre a degradação das terras áridas, semiáridas e subúmidas secas; o Brasil, 
por sua vez, comprometendo-se com a causa, criou o Programa Nacional de Combate à Desertificação e Mitigação dos Efeitos da Seca (PAN/Brasil). Em nosso país, o problema da desertificação afeta, sobretudo, a região Nordeste, sendo a expressão maior da gravidade do fenômeno denominado de Núcleos de Desertificação. A ocorrência da desertificação não deve passar despercebida, pois trata-se de um problema sério que está devastando extensas áreas outrora produtivas e/ou com vegetação nativa. A dimensão dos seus efeitos vai além do âmbito ambiental, passando a ser também de ordem social, econômica e política.

Na região Nordeste, o processo de desertificação já atinge $48 \%$ das terras semiáridas e requer medidas cabíveis para combater a degradação do solo, o desmatamento, entre outros problemas. O estado do Rio Grande do Norte é afetado pelo fenômeno, sobretudo a região Seridó, onde o histórico dos usos da terra associados à expansão da indústria de cerâmica vermelha, a partir da década de 1980, conferiu-lhe um intenso desgaste dos recursos naturais. O núcleo de desertificação existente na região abrange seis municípios, incluindo Parelhas.

O município tem um número significativo de cerâmicas em atividade, o que pode estar agravando o quadro de susceptibilidade à desertificação, pois o consumo amplo e contínuo de lenha, argila e água pode desencadear quadros severos de degradação dos recursos naturais. No entanto, algumas ações governamentais já foram implantadas para mitigar os efeitos da degradação do município, por exemplo, o Núcleo de Desenvolvimento Sustentável (NUDES).

Tanto a comunidade científica quanto as comunidades afetadas podem criar medidas inteligentes e eficazes para o combate e mitigação de seus efeitos. O sucesso do trabalho em equipe depende de ambas as partes: de um lado a população, devidamente sensibilizada e consultada de maneira participativa no processo, deve se comprometer a executar as práticas sustentáveis objetivadas; por outro lado, estudiosos, gestores e/ou órgãos competentes devem se comprometer a auxiliar, fiscalizar, monitorar e acompanhar $\mathrm{o}$ trabalho em desenvolvimento, garantido, assim, o bom desempenho das medidas de combate ao fenômeno da desertificação.

\section{REFERÊNCIAS BIBLIOGRÁFICAS}

AGÊNCIA DE DESENVOLVIMENTO SUSTENTÁVEL DO SERIDÓ - ADESE. Diagnóstico do uso da lenha nas atividades agroindustriais do Território do Seridó/RN. Caicó: ADESE, 2008.

ARAÚJO, J. A. Alterações ambientais em Parelhas, Rio Grande do Norte: metais pesados em sedimentos de drenagens e percepção de comunidades rurais em relação a mudanças na paisagem. 2012. 80 páginas. Dissertação (Mestrado em Desenvolvimento e Meio Ambiente). UFRN. Natal/RN, 2012. 
BEEKMAN G.B. El Programa de Combate a la Desertificación y Mitigación de los Efectos dela Sequía en América del Sur, BID-IICA. In: ABRAHAM, E. M.; BEEKMAN G. B. (Ed.). Indicadores de la Desertificación para América del Sur. Mendosa, Argentina, 2006. BEZERRA, J. M.et al. Utilização de Geotecnologias na Determinação de Áreas Susceptíveis a Desertificação no Estado do Rio Grande do Norte. Revista Brasileira de Geografia Física. v. 4, n. 3. p. 543-561. Recife, 2011.

BRASIL. Ministério da Integração Nacional. Nova delimitação do semi-árido Brasileiro. Brasília, 2005a.

Ministério do Meio Ambiente. Secretaria de Recursos Hídricos. Programa de Ação Nacional de Combate à Desertificação e Mitigação dos Efeitos da Seca PAN/Brasil. Brasília, 2005b.

Ministério do Meio Ambiente. Secretaria de Recursos Hídricos. Atlas das áreas suscetíveis à desertificação do Brasil. Brasília: MMA, 2007.

CAVAlCANTI, E. R.; COUTINHO, S. F. S.; SELVA, V. S. F. Desertificação e desastres naturais na região do semi-árido brasileiro. Revista Cadernos de Estudos Sociais. v. 22, n. 1. p. 1-22. Recife, 2007.

CONTI, J. B. O Conceito de Desertificação. Revista Climatologia e Estudos da Paisagem. v. 3, n. 2. p. 39-52. Rio Claro, 2008.

COSME JÚNIOR, S. Análise de uso e cobertura do solo no município de Parelhas/RN. 2011. 79 páginas. Dissertação (Mestrado em Desenvolvimento e Meio Ambiente). UFRN. Natal/RN, 2011.

FEliPE, J. L. A.; ROCHA, A. P. B.; CARVAlHO, E. A. Atlas Rio Grande do Norte: espaço geo-histórico e cultural. João Pessoa: Grafset, 2011.

FUNDAÇÃO VINGT-UN ROSADO. (Org.). Nono Livro das Secas. Edição especial para o Acervo Virtual Oswaldo Lamartine de Farias. Coleção Mossoroense: Mossoró/RN, 1990.

GARDUÑO, M. A. Tecnologia e Desertificação. In: HARE, K. F. et. al. Desertificação: causas e consequências. Fundação Calouste Gulbenkian, Lisboa, 1992.

HARE, K. F. et al. Desertificação: causas e consequências. Fundação Calouste Gulbenkian, Lisboa, 1992.

INSTITUTO BRASILEIRO DE GEOGRAFIA E ESTATÍSTICA - IBGE. Estados. Rio Grande do Norte. Censo. 2010a. Disponível em: <http://www.ibge.gov.br/estadosat/perfil.php?sigla=rn>. Acesso em: 22 de maio de 2015. Cidades. Parelhas. Censo. 2010b. Disponível em:

<http://www.cidades.ibge.gov.br/xtras/perfil.php?lang=\&codmun=240890\&search=riogrande-do-norte|parelhas >. Acesso em: 22 de maio de 2015.

, Manual Técnico de Pedologia. 2 ed. Rio de Janeiro, 2007.

INSTITUTO NACIONAL DO SEMIÁRIDO - INSA. Sinopse do Censo Demográfico para o Semiárido Brasileiro. Campina Grande/PB, 2012.

LIMA, R. F. S.; LIMA, E. M. Atividades de Base Mineral no Seridó Norte-rio-grandense: aspectos de saúde e meio ambiente. In: FREIRE, E. M. X. (Org.). Recursos Naturais das Caatingas: uma visão multidisciplinar. Natal: EDUFRN, 2009.

LU, Q.; WANG, S. Dust-sand storms in China: disastrous effects and mitigation strategies. 2003. Disponível em: <http://www.fao.org/docrep/ARTICLE/WFC/XII/0859B5.HTM>. Acesso em: 29 de abril de 2015.

MACÊDO, M. K. A penúltima versão do Seridó: uma história do regionalismo seridonense. Natal/RN: EDUFRN, 2012.

MAIA, J. C. L.; COSTA, F. R. Aplicação do "sistema básico de indicadores para a identificação e monitoramento dos processos de desertificação na América Latina e Caribe" nos municípios de Francisco Dantas e Encanto-RN. Revista Geotemas. v. 1, n. 2. p.85-99. Pau dos Ferros/RN, 2011. 
MATALLO JR. H. A desertificação no mundo e no Brasil. In: SCHENKEL, C. S.; MATALLO JR. H. (Org.). Desertificação. Brasília: UNESCO, 1999.

MATALLO JR., H. Indicadores de Desertificação: histórico e perspectivas. Brasília: UNESCO, 2001.

MORAIS, I. R. D. et al. A desertificação no Seridó Potiguar. In: MOREIRA, E.; TARGINO, I. (Org.). Desertificação, desenvolvimento sustentável e agricultura familiar: recortes no Brasil, em Portugal e na África. João Pessoa: Editora Universitária da UFPB, 2010.

NASCIMENTO, J. A. O circuito espacial da indústria de cerâmica vermelha no Seridó Potiguar. 2011. 135 páginas. Dissertação (Mestrado em Geografia). Natal/RN, 2011.

NASCIMENTO, F. R. O fenômeno da desertificação. Goiânia: Editora UFG, 2013.

ORGANIZAÇÃO DAS NAÇÕES UNIDAS - ONU. Convención de las Naciones Unidas de lucha contra la desertificación en los países afectados por sequía grave o desertificación, en particular en África. Asamblea General. 1994. Disponível em: <http://www.unccd.int/en/about-the-convention/Pages/About-the-Convention.aspx >. Acesso em 17 de março de 2015.

PEREZ-MARIN, A. et al. Núcleos de desertificação no semiárido brasileiro: ocorrência natural ou antrópica?. Revista Parcerias Estratégicas. v. 17, n. 34, p. 87-106. Brasília-DF, 2012.

PIUAI, Secretaria de Estado do Meio Ambiente e Recursos Hídricos. Panorama da Desertificação no Estado do Piauí. [Relatório de Consultoria]. Teresina/PI, 2005.

RIO GRANDE DO NORTE. Secretaria de Recursos Hídricos. Programa de Ação Estadual de Combate à Desertificação e Mitigação dos Efeitos da Seca do Rio Grande do Norte PAE/RN. Natal/RN: 2010.

Secretaria de Recursos Hídricos. Panorama da Desertificação no Estado do Rio Grande do Norte. Natal/RN: 2005a.

, Secretaria de Recursos Hídricos. Planos e Projetos Pilotos de Recuperação de

micro-bacias hidrográficas: micro-bacia hidrográfica do Rio Cobra. [Termo de Referência]. Natal/RN: 2005b.

ROSÁRIO, L. Indicadores de desertificação para Portugal continental. Editideias: Lisboa, 2004.

SALES, M. C. L. Evolução dos Estudos de Desertificação no Nordeste Brasileiro. Revista Geousp: espaço e tempo. n. 11, p. 115-126, São Paulo, 2002.

SAMPAIO, E. V. S. B.; ARAÚJO, M. S. B.; SAMPAIO, Y. S. B. Impactos ambientais da agricultura no processo de desertificação no Nordeste do Brasil. Revista de Geografia. n 1, v. 22, p. 90-112, Recife, 2005.

SEELY, M. K. Can science and community action connect to combat desertification?. Journal of Arid Environments. n. 39, p. 267-277, 1998.

SERVIÇO DE APOIO ÀS MICRO E PEQUENAS EMPRESAS DO RIO GRANDE DO NORTE - SEBRAE/RN. Diagnóstico da indústria de cerâmica vermelha do Rio Grande do Norte: relatório final. Natal, 2013.

SIEBER, S. S.; MEDEIROS, P. M.; ALBUQUERQUE, U. P. Local Perception of Environmental Change in a Semi-Arid Area of Northeast Brazil: a New Approach for the Use of Participatory Methods at the Level of Family Units. Journal of Agricultural and Environmental Ethics, n. 24. p. 511-531, 2010.

SZILAGYI, G. Diagnóstico Ambiental do Processo de Desertificação no município de Lajes/RN. 2007. 101 páginas. Dissertação (Mestrado em Geografia). UFRN. Natal/RN, 2007. TRAJANO, V. A. Um olhar sobre as comunidades rurais de Cachoeira, Juazeiro e Santo Antonio da cobra no município de Parelhas/RN: elementos para uma análise de processos de desertificação. 2005. 163 páginas. Dissertação (Mestrado em Geografia). UNB. Brasília, 2005. 
UNITED NATIONS CONVENTION TO COMBAT DESERTIFICATION - UNCCD. Desertification the invisible front line. 2014. Disponível em: <http://www.unccd.int/en/mediacenter/MediaNews/Pages/highlightdetail.aspx?HighlightID=275>. Acesso em 10 de abril de 2015.

.Desertificación: una síntesis visual. 2012 Disponível em: 〈http://www.unccd.int/Lists/SiteDocumentLibrary/Publications/Desertification-P.pdf〉. Acesso em: 6 de maio de 2015. UNITED NATIONS FRAMEWORK CONVENTION ON CLIMATE CHANGE UNFCCC. Initial National Communication to the United Nations Framework Convention on Climate Change. 2002. Disponível em: $<$ http://unfccc.int/resource/docs/natc/namnc1.pdf>. Acesso em: 25 de abril de 2015. VERDUM, R. et al. Desertificação: questionando as bases conceituais, escalas de análise e consequências. Revista Geographia. v. 3, n. 6, p. 1-9, 2001.

WU, B.; CI, L. J. Landscape change and desertification development in the Mu Us Sandland, Northern China. Journal of Arid Environments. n. 50, p. 429-444, 2002.

YANG, X. et al. Desertification assessment in China: an overview. Journal of Arid Environments. n. 63, p. 517-531, 2005.

ZHA, Y.; GAO, J. Characteristics of desertification and its rehabilitation in China. Journal of Arid Environments n. 37, p. 419-432, 1997. 